\title{
Endovascular coiling: An important technique in the management of gastrointestinal hemorrhage
}

\author{
Juergen Feisthammel MD¹, Dominik Fritzsch MD², Sebastian Weis MD , \\ Joachim Mossner MD ${ }^{1}$, Albrecht Hoffmeister MD ${ }^{1}$
}

\begin{abstract}
44-year-old patient with abdominal pain and hematemesis was Aadmitted to hospital. On gastroscopy, a large duodenal ulcer with a visible vessel was found (Figure 1, panel A, arrowhead). To prevent rebleeding, a hemoclip was placed on this vessel. This caused reactivation of the bleeding. After injection of epinephrine (1:10,000 dilution) and application of additional hemoclips, the bleeding was stopped (Panel B). The patient was transferred to the intensive care unit for surveillance. Just a few hours later, major rebleeding occurred.
\end{abstract}

Because endoscopic therapy was not successful, an emergency endovascular coiling of the gastroduodenal artery was performed. This procedure stopped the bleeding. On endoscopic control one week later, the patient's condition was stable. The coils were visible at the site of the ulcer (Panel C). Three months later, the patient was controlled in an outpatient setting (Panel D). No further bleeding has occurred since.

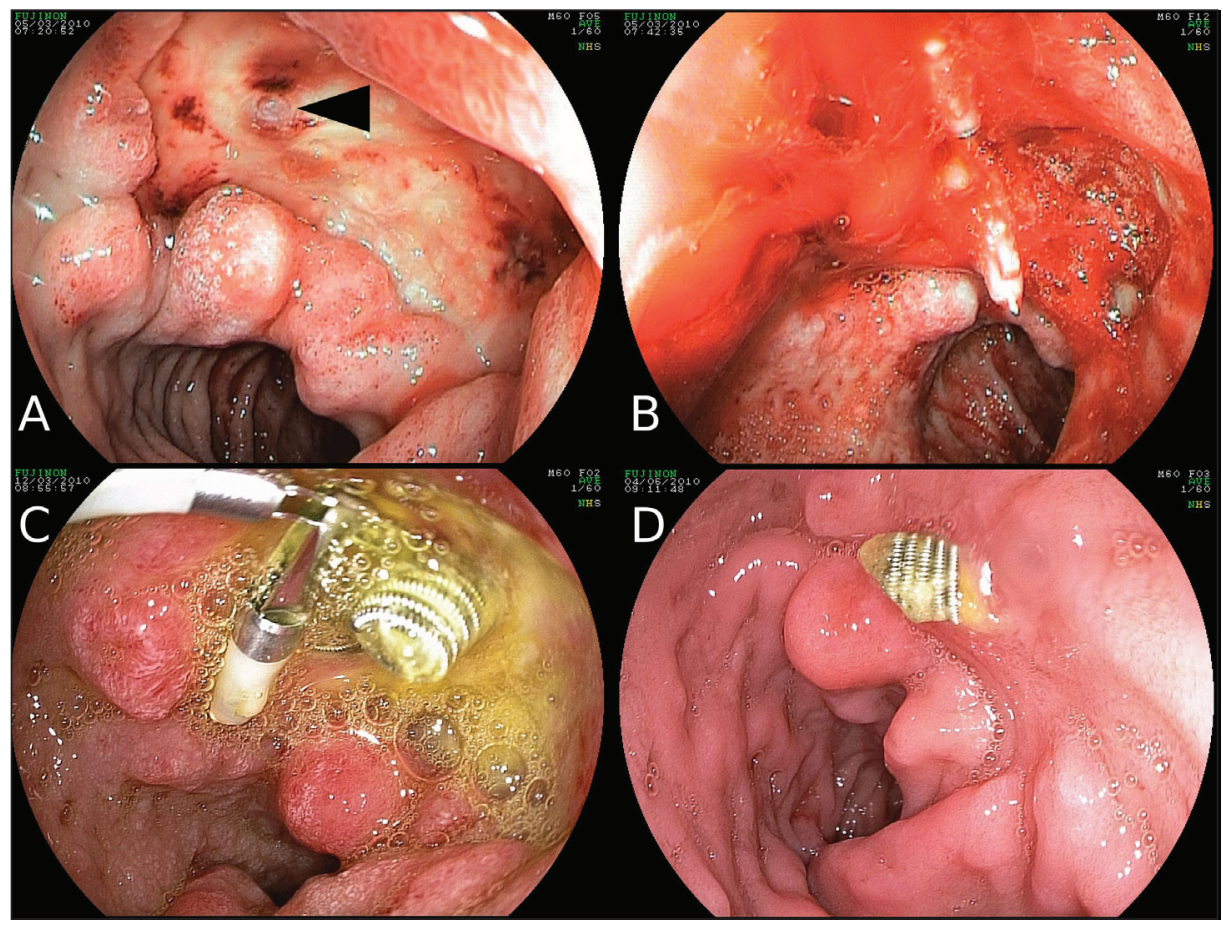

The Canadian Journal of Gastroenterology is now considering a limited number of submissions for IMAGE OF THE MONTH. These are based on endoscopic, histological, radiological and/or patient images, which must be anonymous with no identifying features visible. The patient must consent to publication and the consent must be submitted with the manuscript. All manuscripts should be practical and relevant to clinical practice, and not simply a case report of an esoteric condition. The text should be brief, structured as CASE PRESENTATION and DISCUSSION, and not more than 700 words in length. A maximum of three images can be submitted and the number of references should not exceed five. The submission may be edited by our editorial team.

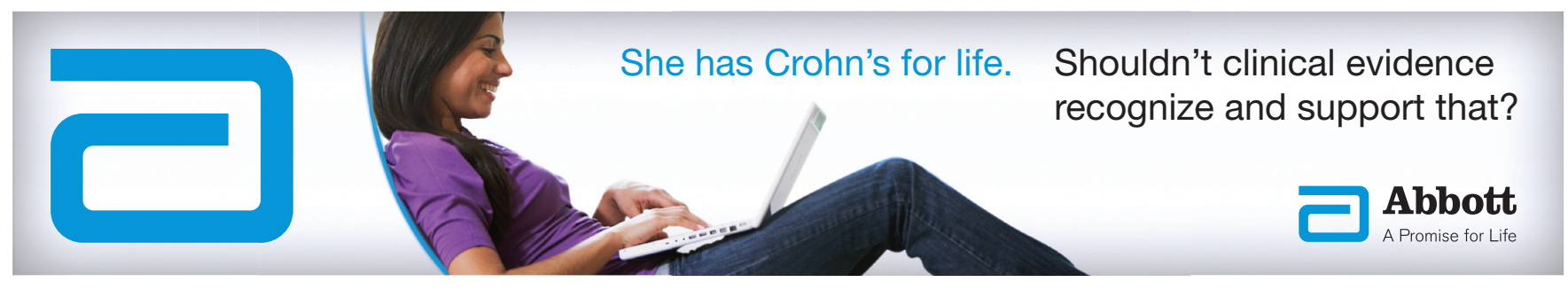

${ }^{1}$ Department of Medicine, Dermatology and Neurology, Division of Gastroenterology and Rheumatology; ${ }^{2}$ Department of Diagnostic Radiology,

University of Leipzig, Leipzig, Germany

Correspondence: Dr Juergen Feisthammel, Department of Internal Medicine, University of Leipzig, Liebigstr, 20, Sachsen 04103, Germany.

Telephone 49-341-9712374, fax 49-341-9712219, e-mail juergen.feisthammel@medizin.uni-leipzig.de

Received for publication May 10, 2012. Accepted May 13, 2012 


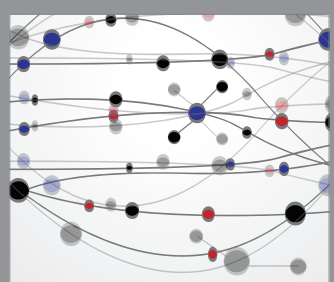

The Scientific World Journal
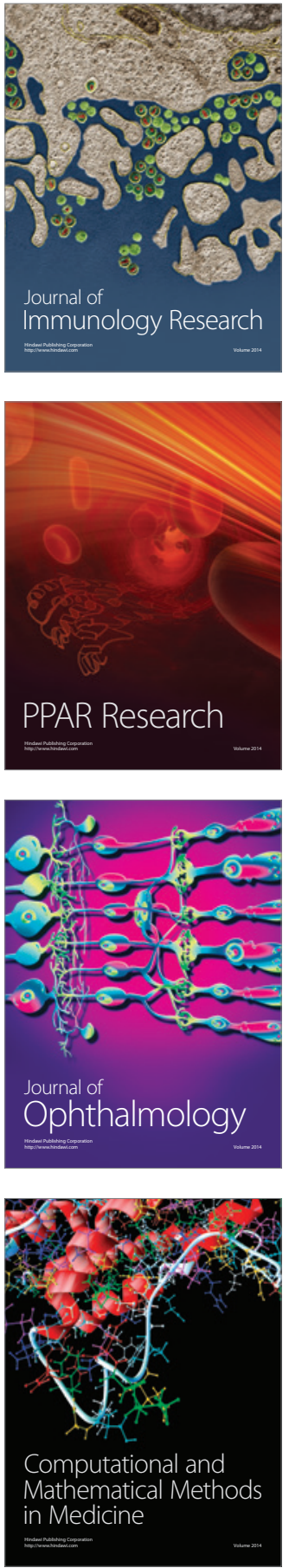

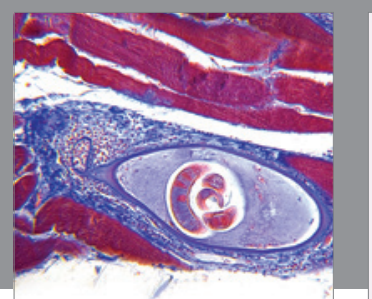

Gastroenterology Research and Practice

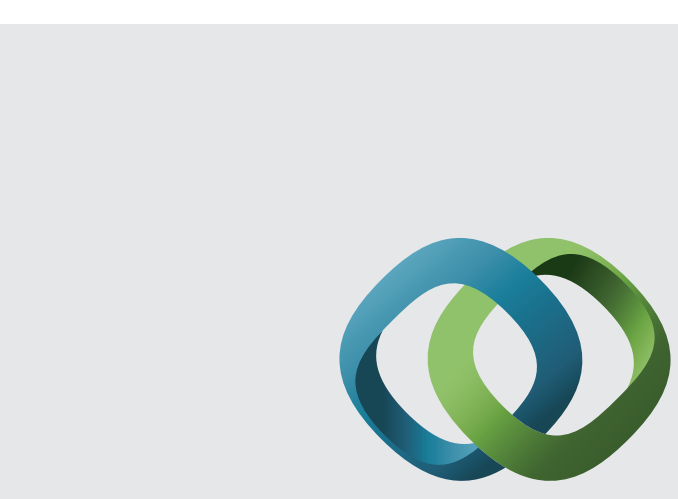

\section{Hindawi}

Submit your manuscripts at

http://www.hindawi.com
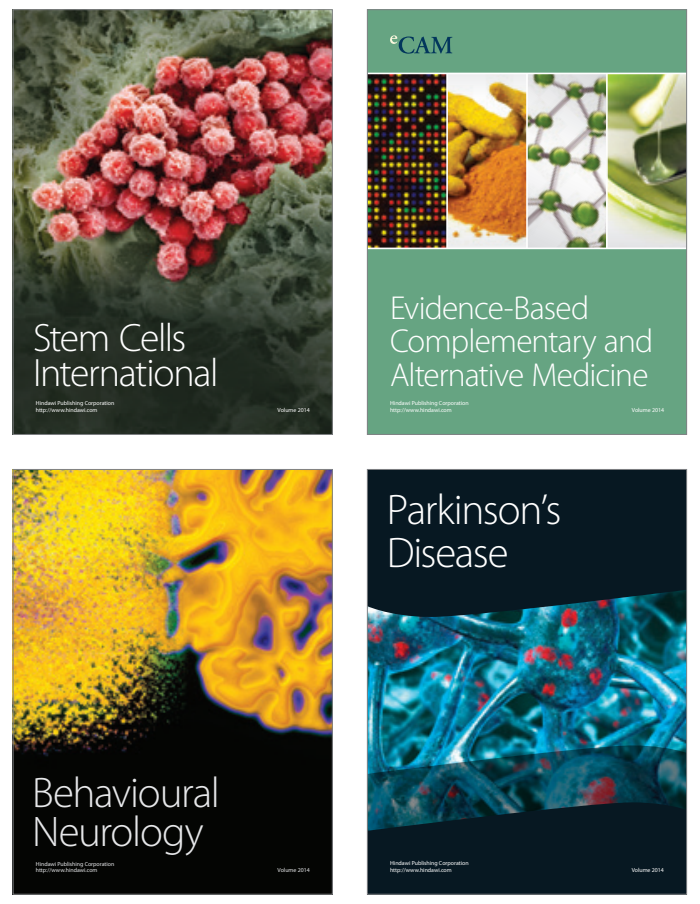
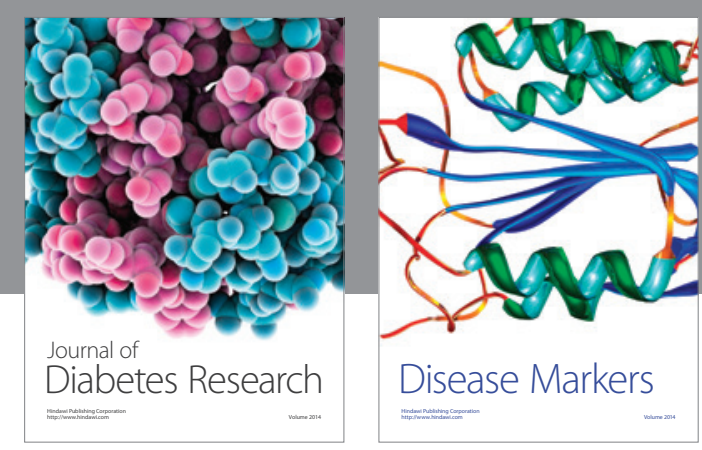

Disease Markers
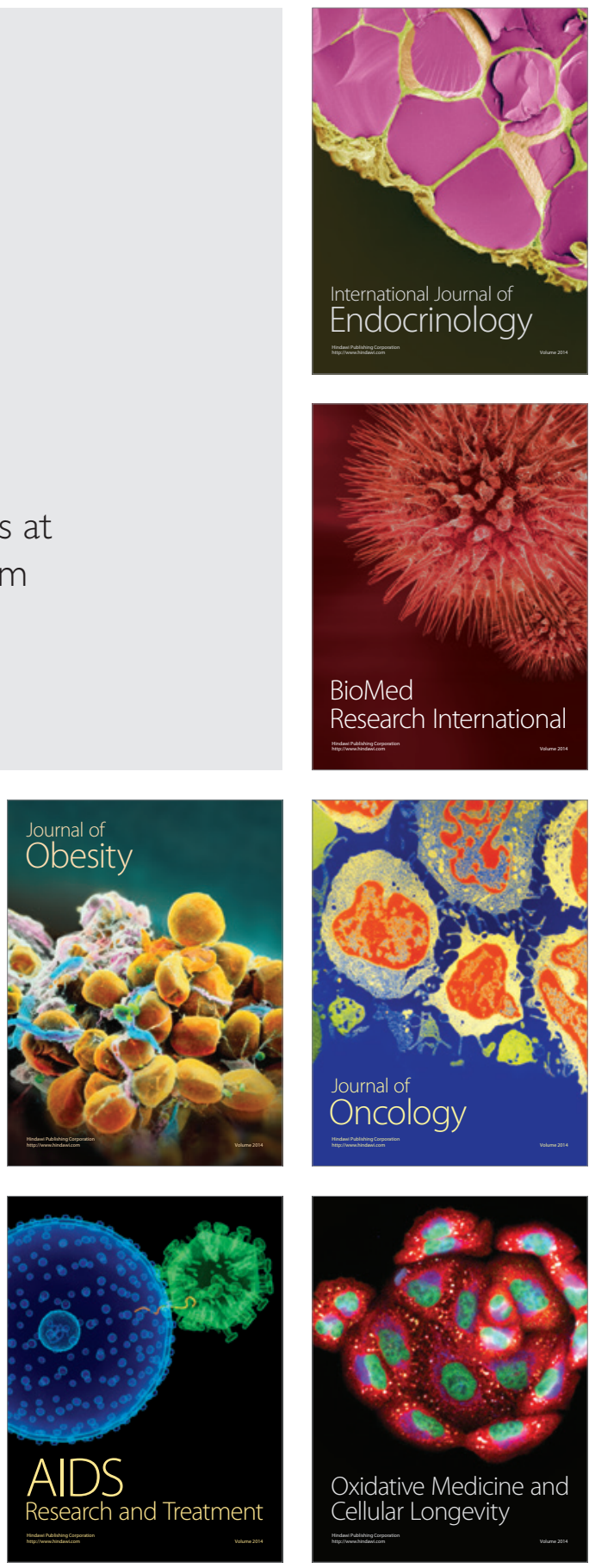